\title{
Historical Elimination of Onchocerciasis from Victoria Nile Focus in Central Uganda Verified Using WHO Criteria
}

\author{
Moses N. Katabarwa, ${ }^{1 *}$ Peace Habomugisha, ${ }^{2}$ Annet Khainza, ${ }^{2}$ David W. Oguttu, ${ }^{3}$ Edson Byamukama, ${ }^{2}$ James Katamanywa, ${ }^{4}$ \\ Christine Nahabwe, ${ }^{3}$ Monica Ngabirano, ${ }^{3}$ Paul Akampurira, ${ }^{3}$ Lauri Bernard, ${ }^{1}$ Thomas R. Unnasch, ${ }^{5}$ and Frank Richards ${ }^{1}$ \\ ${ }^{1}$ The Carter Center, Atlanta, Georgia; ${ }^{2}$ The Carter Center, Kampala, Uganda; ${ }^{3}$ Vector Control Division, Ministry of Health, Kampala, Uganda; \\ ${ }^{4}$ Vector Control, Kabarole, Uganda; ${ }^{5}$ Center for Global Health Infectious Disease Research, University of South Florida, Tampa, Florida
}

\begin{abstract}
Uganda has verified elimination of seven onchocerciasis foci since 2007 when the nationwide onchocerciasis elimination policy was launched. However, the Victoria Nile focus (which was eliminated in the early 1970 s) had not been verified. The objective of this study was to verify this focus to the WHO verification guidelines and bring it in line with recently eliminated foci. Vector control with dichlorodiphenyltrichloroethane was the main intervention used at the Victoria Nile from the 1950s to the 1970s. Historical fly collection sites along River Nile were identified for recent fly collection. Relevant health workers near the sites were trained to supervise fly collection activity. With support from communities, fly collectors were identified, trained, and equipped to collect Simulium flies for at least a year. A total of 854 Simulium flies were collected and analyzed by polymerase chain reaction to detect Onchocerca volvulus DNA. The communities and their leaders provided consent for the collection of dry blood spots (DBS) from children younger than 10 years for investigation of recent exposure to the disease. A total of 2,953 DBS were collected and analyzed by OV16 ELISA to detect the presence of $\operatorname{lgG}_{4}$ antibodies recognizing the OV16 antigen. The results showed that none of the flies carried O. volvulus DNA. Similarly, all the children were OV16 negative, showing no exposure to onchocerciasis. All the flies collected were identified as Simulium adersi, which is not a known vector for O. volvulus. The results confirmed that onchocerciasis and its vector Simulium damnosum had been eliminated in the Victoria Nile focus.
\end{abstract}

\section{INTRODUCTION}

Onchocerciasis is a human disease caused by infection with the filarial worm Onchocerca volvulus, which is transmitted from person to person by the bites of female black flies that breed in fast-flowing rivers and streams. In Uganda, Simulium damnosum was documented as early as 1863 by John $\mathrm{H}$. Speke, the first European to see the source of River Nile. ${ }^{1} \mathrm{He}$ experienced sharp and painful bites of Simulium flies and recorded vast numbers of flies along many waterfalls and rapids which provided ideal conditions for breeding. Simulium fly biting was estimated at 300 flies per man-hour. This had a negative impact on agriculture in a fertile area that was expected to be a major food basket for Uganda. ${ }^{1,2}$ The Victoria Nile focus is the place of original description of type locality of S. damnosum s.I by Christy. ${ }^{3}$ Simulium damnosum s.s was documented as the main vector of onchocerciasis. ${ }^{4}$ However, a decision to retain the name S. damnosum for the Nile cytotype was because of its extreme variability of its habitats and too slight morphological variations from widely distributed localities, resulting into taxonomists referring to it as a single species. ${ }^{5,6}$ The areas affected by the disease covered the present districts: Buikwe, Jinja, Kamuli, Kayunga, and Mukono. ${ }^{7,8}$

Simulium flies in this focus bred along a $70-\mathrm{km}$ stretch on the River Nile between Lake Victoria and Lake Kyoga (Figure 1). Life in this focus was described as unbearable, as O. volvulus infection affected almost $99 \%$ of the population. Almost all the people suffered from the disease with various forms of onchocercal dermatitis. ${ }^{9,10}$ River Nile flowed through Mabira, a vast natural tropical forest where many inhabitants suffered from dwarfism commonly referred to as "Nakalanga" (meaning, "grilling") syndrome. It was suspected to be due to pituitary malfunction caused by onchocerciasis. ${ }^{11,12}$ In the

*Address correspondence to Moses N. Katabarwa, The Carter Center, 453 John Lewis Freedom Parkway, Atlanta, GA 30307. E-mail: moses.katabarwa@cartercenter.org early 1950s when control activities were launched, the population of Victoria Nile focus was about 260,000 people, and by 1974 when onchocerciasis had been eliminated, it had grown to about 400,000 people. ${ }^{3,13}$ Since then, the population has grown about eight times, and in 2019 , it was estimated to be about 3.2 million people.

Diethylcarbamazine citrate was available for treatment but tended to result in violent allergic reactions because of the rapid release of parasite antigens, and so was not used regularly. Control of onchocerciasis was mainly by vector control using dichlorodiphenyltrichloroethane (DDT). ${ }^{2}$ Vector control by ground larviciding with DDT using a fire launch commenced in 1951. A detailed account of vector control from 1951 to 1973 is shown in Table $1 .^{14}$ A water flow of $17,000 \mathrm{cu}$ per second was treated at $0.45 \mathrm{ppm}$ DDT for 30 minutes in 12 weekly applications. The adult Simulium fly population was initially reduced by $90 \%$ in 3 years. More DDT was applied in 1956 at 0.2 ppm for 30 minutes using the new Owen Falls hydroelectric power dam spillway. No adult flies were observed over the course of the next 4 years after $1956 .{ }^{15}$ River Nile presented an exceptionally favorable situation, as no breeding occurred upstream of the last falls from Owen Falls dam toward Lake Kyoga. ${ }^{16}$ There were no infested tributaries downstream. Larviciding applied at the dam cleared the larval stages of $S$. damnosum along the entire stretch of the river, where breeding was favorable. ${ }^{17}$

As a result of the larviciding treatments, the prevalence of O. volvulus infection among children younger than 10 years dropped from $53 \%$ in 1952 to $2 \%$ in 1962. In 1967, the prevalence in children between the age of 5 and 14 years was $0.5 \%$ in previously high-transmission areas. ${ }^{14}$ Within $80 \mathrm{~km}$ of the river, skin snip microfilariae prevalence was reduced from $17 \%$ in 1967 to less than $0.2 \%$ in $1974 .{ }^{18}$ It was reported that 12 weekly doses from 1961 to mid-1965 were administered in some sites, but flies returned rapidly in large numbers in August 1966. Full DDT dosing was reinstated in June/July 1967 and continued into 1973 using the dam spillway (Table 1). It 


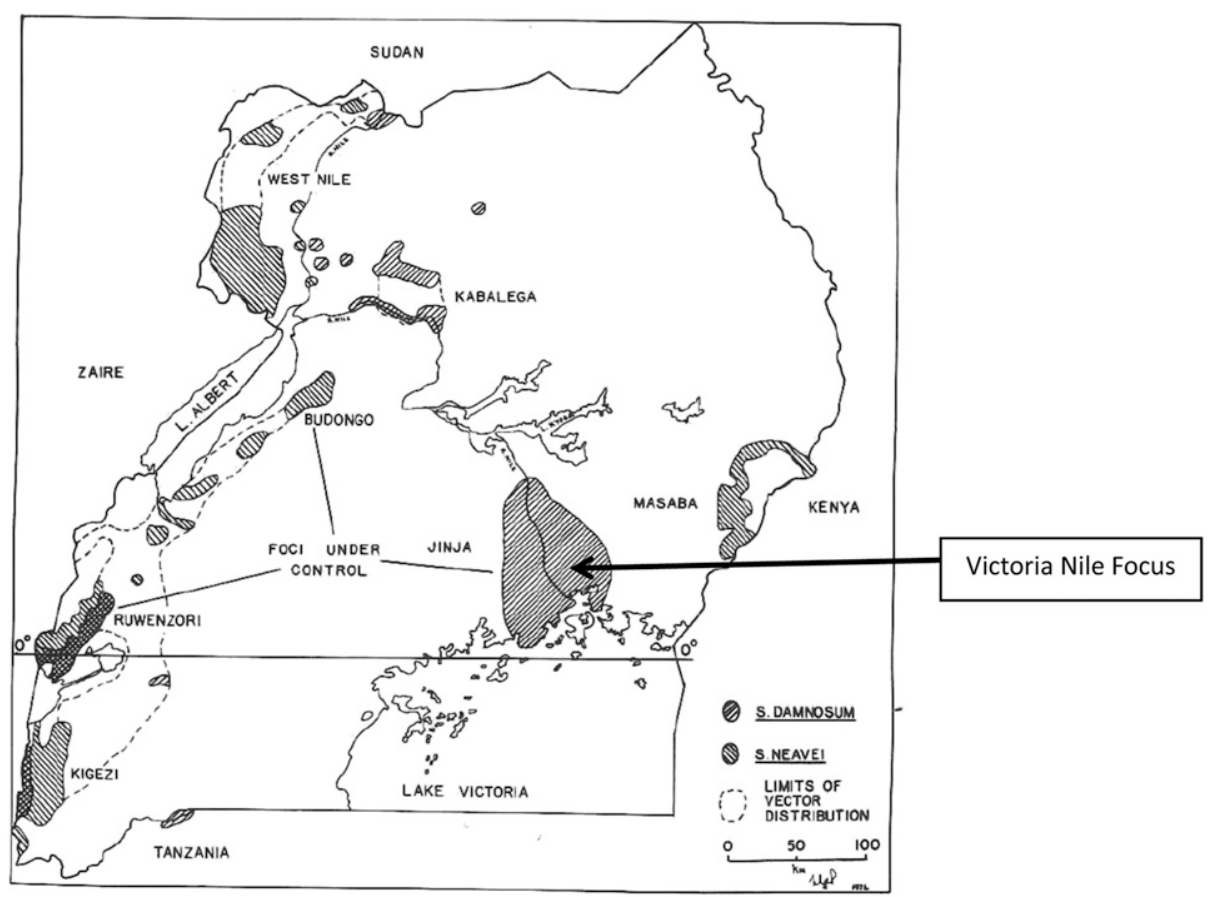

FIGURE 1. Map showing the Victoria Nile focus between Lake Victoria and Lake Kyoga (Prentice MA [ed.]) in ref. 14

was observed that daily river fluctuation using the dam spillway also had a substantial impact on fly biting density, and no Simulium vectors were observed from June 1967 to 1973. After 1973, political instability in the country became the order of the day, and detailed records were no longer kept. However, sanitary larviciding continued until 1977 with a few remaining vector control staff of the Ministry of Health. Although it was claimed that the Victoria Nile Onchocerciasis focus had been eliminated in the early 1970s, the WHO guidelines for verification of onchocerciasis elimination had not been applied. ${ }^{19}$
The Uganda Onchocerciasis Elimination Expert Advisory Committee (UOEEAC), a national technical committee, recommended that the elimination of onchocerciasis in the Victoria Nile focus be verified on the current WHO criteria. The ninth session of the UOEEAC meeting requested a report on the findings at its tenth session in August 2017. The present study describes how Uganda implemented the required surveys so as to comply with the $\mathrm{WHO}$ verification guidelines in verifying the elimination of onchocerciasis in the Victoria Nile focus where $S$. damnosum sl was the vector.

TABLE 1

Summary of Simulium control on the Victoria Nile, Uganda, 1951-1973, by Prentice MA (ed.) in ref. 14

\begin{tabular}{|c|c|c|c|c|c|}
\hline Date & Formulation of DDT & Target dose and number of doses & $\begin{array}{l}\text { Kilos of } \\
\text { pp-DDT }\end{array}$ & Method & Effect \\
\hline $\begin{array}{c}\text { January } \\
1951\end{array}$ & $10 \%$ solution & $20 \mathrm{mg} / \mathrm{m}^{2} \times 8$ (on banks) & No record & Airspray & Temporary reduction \\
\hline June 1952 & $\begin{array}{l}25 \% \text { mayonnaise } \\
\text { emulsion }\end{array}$ & $0.45 \mathrm{ppm} \times 12$ & 5,832 & Fire launch & 90\% reduction until 1956 \\
\hline $\begin{array}{l}\text { March } \\
1956\end{array}$ & $12 \%$ solution & $0.55 \mathrm{ppm} \times 10.33 \mathrm{ppm} \times 12$ & 3,150 & Drip into dam spillway & Flies absent up to 1960 \\
\hline $\begin{array}{c}\text { January } \\
1961\end{array}$ & $12 \%$ solution & $0.1 \mathrm{ppm} \times 12$ & 1,080 & Drip into dam spillway & Flies absent up to 1964 \\
\hline April 1964 & $\begin{array}{l}25 \% \text { E.C. } \\
12 \% \text { solution } \\
25 \% \text { E.C. }\end{array}$ & $\begin{array}{l}0.05 \mathrm{ppm} \times 2^{\mathrm{a}} \\
0.1 \mathrm{ppm} \times 1^{\mathrm{a}} \\
0.025 \mathrm{ppm} \times 1^{\mathrm{a}}\end{array}$ & 1,726 & Drip into dam spillway & $\begin{array}{l}\text { Larvae-eliminated flies returned } \\
\text { at low density after } 4 \text { months }\end{array}$ \\
\hline May 1965 & & $\begin{array}{l}0.035 \mathrm{ppm} \times 1 \\
0.1 \mathrm{ppm} \times 1 \\
0.06 \mathrm{ppm} \times 11\end{array}$ & 2,043 & Drip into dam spillway & $\begin{array}{l}\text { Larvae-eliminated flies returned } \\
\text { at low density after } 6 \text { months }\end{array}$ \\
\hline $\begin{array}{l}\text { October } \\
1966\end{array}$ & $25 \%$ E.C. & $0.035 \mathrm{ppm} \times 1^{\mathrm{a}}$ & 108 & Drip into dam spillway & Temporary reduction \\
\hline June 1967 & $25 \%$ E.C. & $0.07 \mathrm{ppm} \times 6$ & $756^{\mathrm{b}}$ & $\begin{array}{l}\text { Drip into dam spillway and } \\
\text { turbine exhaust }\end{array}$ & $\begin{array}{l}\text { Flies effectively absent up to } \\
1970\end{array}$ \\
\hline May 1970 & $25 \%$ E.C. & 0.07 ppm & $756^{\mathrm{b}}$ & “ & $\begin{array}{l}\text { Flies effectively absent up to } \\
1973\end{array}$ \\
\hline July 1973 & $25 \%$ E.C. & ? & ? & ? & $?$ \\
\hline
\end{tabular}




\section{METHODS}

Study area. The Victoria Nile focus was approximately $80 \mathrm{~km}$ from the source of River Nile near Jinja town extending to a point where the river became sluggish before reaching Lake Kyoga. The focus extended about $20 \mathrm{~km}$ east and west of the river, covering an area about 3,200 km (Figures 1 and 2). The area is 1,030-1,150 $\mathrm{m}$ above sea level. Toward Lake Kyoga, the river is sluggish with Cyperus papyrus, making it unsuitable for breeding of vectors of onchocerciasis. In the 1950s, the focus was largely covered by Mabira, a natural tropical forest; currently, $300 \mathrm{~km}^{2}$ of the forest cover remains, mainly on the western part of River Nile.

Serological assessments. Dry blood spots (DBS) were collected from communities distributed in 12 parishes in Jinja, Kamuli, and Kayunga districts of the Victoria Nile focus (Figure 2). These were first-line or "high-risk" parishes along the stretch of River Nile where Simulium breeding used to occur, and is still ongoing. Preparation of finger-prick blood spots was performed following standard sterile procedures. In every village in a sampled parish, all children younger than 10 years had an equal chance of being selected. Blood was collected on Whatman filter paper No.2 squares (Sigma). Each sample was labeled with an identification number and allowed to air-dry, and then packed and stored in sealed plastic bags with a silica gel desiccant at $-20^{\circ} \mathrm{C}$. The maximum number of children available in the focus for collection of DBS was 2,953. Analysis with OV16 ELISA was used to measure the presence of $\operatorname{lgG}_{4}$ antibodies recognizing the OV16 antigen in the eluted blood spot. ${ }^{20}$

Nearest Simulium fly breeding sites along River Nile downstream of Lake Kyoga. Dry blood spots from children younger than 10 years were collected from Kiryandongo district, close to the breeding sites along River Nile downstream of Lake Kyoga. This is the closest place from Victoria Nile focus where conditions favor the breeding of Simulium vectors. A total of 3,302 DBS samples were collected in parishes along River Nile in Kiryandongo district from children younger than 10 years. These were analyzed following the procedures described earlier.

Entomological assessment. A report showing the sequential use of river dosing with DDT and its impact on Simulium flies from 1951 to 1973 was provided from historical records (Table 1). ${ }^{14}$ Six historical fly collection sites (Busowoko, Bumegere, Kalagala, Itanda, Isimba, Izaniro, and Owen Falls) were identified (Figure 2) and prospected. Riverine prospections were carried out on a stretch of River Nile from Owen Falls dam to Mbulamuti in Kamuli district. The entomological team investigated the entire stretch where Simulium breeding was expected with close attention to areas around rapids and falls. Also, submerged substrates, such as stones, trailing vegetation, and logs, in the river where Simulium early stages are likely to be attached were investigated. Within the

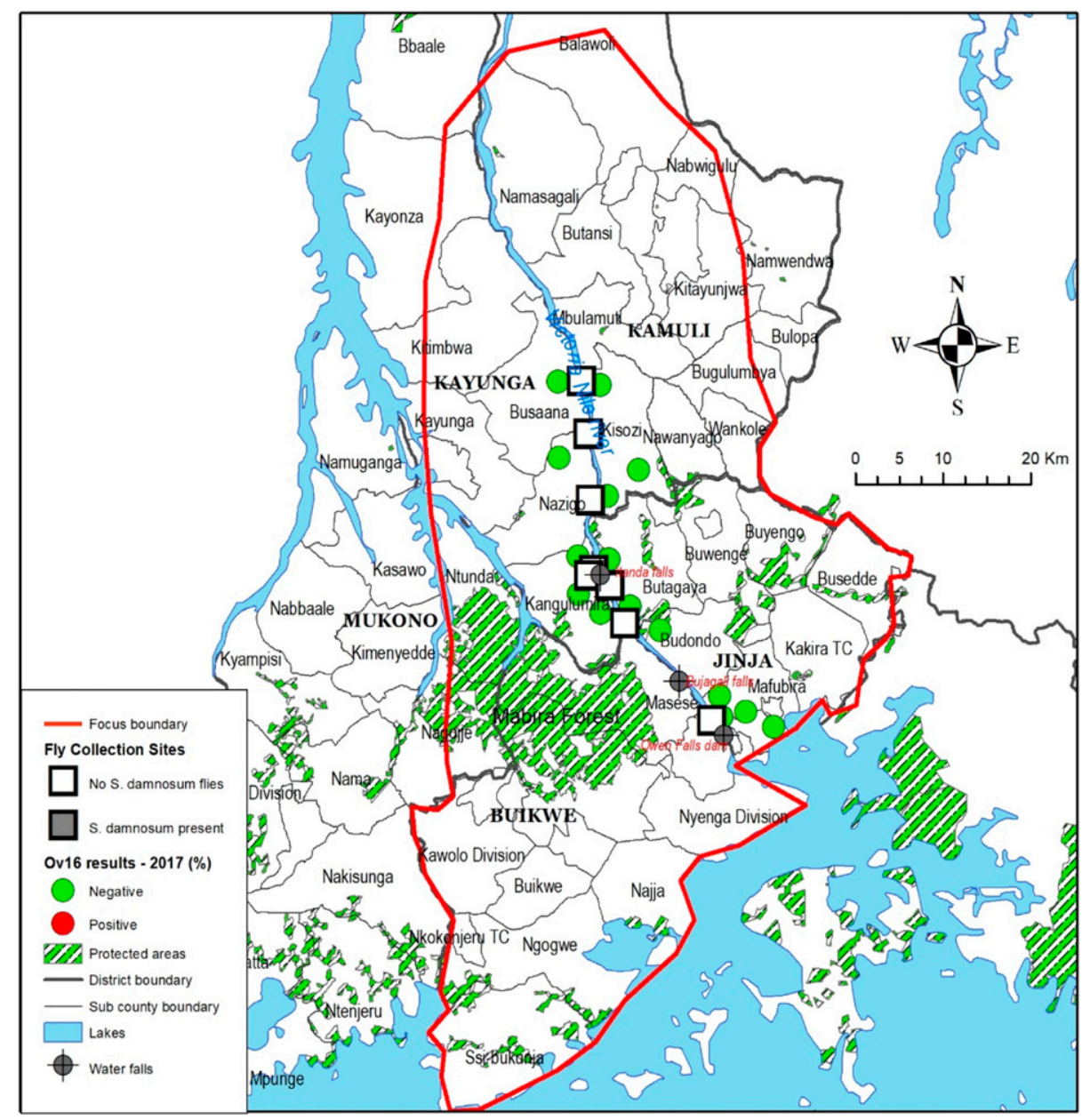

FIGURE 2. Map of Victoria onchocerciasis focus that was eliminated in the early 1970 s. 


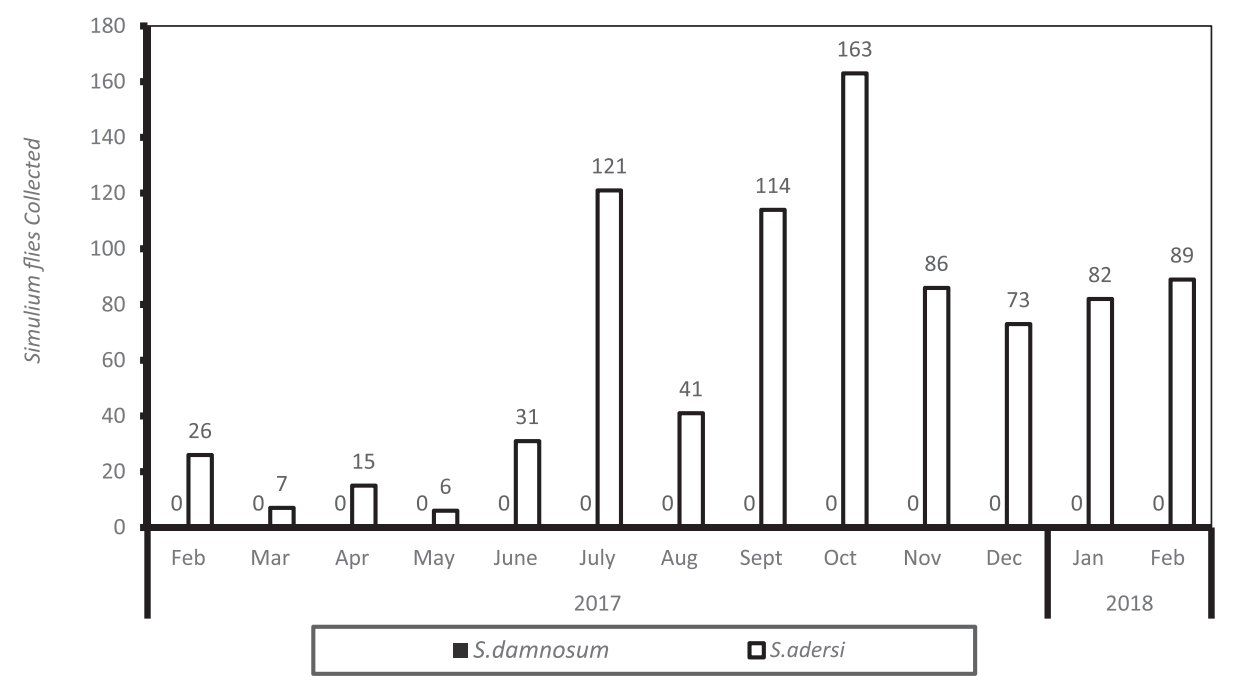

FIGURE 3. Number of Simulium adersi flies and Simulium damnosum collected in the Victoria Nile focus.

stretch where breeding was expected, the entomological team found submerged substrates covered with epiphytic and epilithic growth of algae, as was observed in 1975., 1 The prospections were carried out widely along an $80-\mathrm{km}$ stretch between Owen Falls and Mbulamuti, and later followed every 7 days every month for a year.

The decision to follow-up all the six historical flies and one more collection site was made, and fly collection was established. Resident fly collectors were identified, recruited, and trained to collect Simulium flies (Figure 2). Two fly collectors were trained, equipped, and stationed at each site. Fly collection at each of the eight sites along River Nile was carried out from 700 to 1,800 hours 2 days per week; 4 weeks per month, which equals 8 days per site per month; or 88 days over a period of 13 months (1,144 hours; Figure 3$)$. The flies were preserved in absolute ethanol, labeled, and transported to the laboratory of the Ministry of Health in Kampala where they were identified. Anthropophilic Simulium flies collected at human bait were identified according to Freeman and deMeillion $^{21}$; and Crosskey. ${ }^{22}$

The extraction of DNA was performed using the magnetic bead method. ${ }^{23} A$ total of 854 Simulium flies (nine pools, each containing a maximum of 100 flies) were analyzed. The flies were morphologically identified, and their heads were tested to determine the fly infectivity rate by $\mathrm{O}-150$ polymerase chain reaction (PCR) to detect O. volvulus DNA. Pool Screen ${ }^{\circledR}$ (version 2.0; University of 238 Alabama, Birmingham, AL) was applied to estimate the proportion of positive heads and the associated $95 \% \mathrm{Cls}^{23}$

Ethical approval. The study was classified by Emory University institutional review board as a routine programmonitoring activity and, therefore, "non-research." It was

TABLE 2

Ov16 results from children younger than 10 years in the Victoria Nile focus (2017)

\begin{tabular}{lccc}
\hline District & Children younger than 10 years & No. positive & \% positive $(95 \% \mathrm{Cl})$ \\
\hline Jinja & 1,595 & 0 & $0(0-0.003)$ \\
Kamuli & 652 & 0 & $0(0-0.007)$ \\
Kayunga & 706 & 0 & $0(0-0.007)$ \\
Total & 2,953 & 0 & $0(0-0.002)$ \\
\hline
\end{tabular}

approved by the Ministry of Health, Uganda, as a routine program evaluation. Before implementation of the surveys, district and community leaders were educated about onchocerciasis and the need for verifying its elimination. Community leaders were responsible for informing and organizing meetings in selected communities. The communities were informed about the dates and time for the meetings in their respective communities. Every selected community was visited by the study team. The study educated community members about the disease and informed them about the importance of verifying elimination of the disease. Verification included serological and entomological surveys. Community members had time to ask questions or seek for clarification. Later, the community members and the community leaders reached a consensus that the surveys be conducted. During the surveys, selected subjects consented as individuals to participate in the serological surveys. The parents consented for their young children. However, when children feared being pricked, they opted out without repercussions. A few adults participated as vector collectors after consenting to work at fly collection sites within their respective communities.

\section{RESULTS}

Serological verification. A total of 2,953 serum samples from children younger than 10 years residing in the formerly hyperendemic communities were tested using the OV16 ELISA, and none were found positive for exposure to onchocerciasis (Table 2).

Entomological verification. A total of 854 Simulium flies were collected every month over a period of 13 months indicting a perennial pattern of breeding and possible biting (Figure 3). All the flies were identified as Simulium adersi, which is not a known vector for $O$. volvulus. No $S$. damnosum flies were collected, and when the 854 S. adersi were analyzed by PCR, all were negative. The point estimate of the annual biting rate was 37 for S. aldersi, and the upper bound of the $95 \% \mathrm{Cl}$ for the ATP was 1.05 .

Nearest Simulium fly breeding sites along River Nile downstream of Lake Kyoga. None of the 3,302 children tested with OV16 ELISA in the Kiryandongo district close to Simulium breeding sites were positive (Table 3 ). 
TABLE 3

Ov16 results from children younger than 10 years in Kiryandongo district adjacent to River Nile (2016)

\begin{tabular}{lccc}
\hline \multicolumn{1}{c}{ Parish } & No. assessed & No. positive & \% positive $(95 \% \mathrm{Cl})$ \\
\hline Diima & 1,143 & 0 & $0(0-0.004)$ \\
Nyamahasa & 1,023 & 0 & $0(0-0.005)$ \\
Kakwokwo & 1,136 & 0 & $0(0-0.004)$ \\
Total & 3,302 & 0 & $0(0-0.001)$ \\
\hline
\end{tabular}

\section{DISCUSSION}

Serological data suggest that there has been no exposure to O. volvulus in children younger than 10 years, although the entomological studies did not reveal any evidence for vector Simulium flies re-infesting the focus. Simulium flies that were collected did not have any evidence for the presence of $O$. volvulus parasites. Recent entomological and serological results following the $\mathrm{WHO}$ and Uganda guidelines agreed with historical reports that the vector $S$. damnosum and onchocerciasis had been eliminated from the Victoria Nile focus. ${ }^{24}$ Simulium adersi was the only species collected in the former Victoria Nile Onchocerciasis focus. S. adersi found elsewhere in Cameroon, Tanzania, and Uganda has never been shown to be a vector for O. volvulus. ${ }^{25}$ Wegesa ${ }^{26}$ demonstrated that $S$. adersi in a controlled experiment ingest microfilariae, and about $5.4 \%$ (57) of 1,052 flies used in the experiment survived to complete O.voluvulus development. ${ }^{26}$ Fortunately, there was no evidence of $O$. volvulus in the focus, and any bites of $S$. adersi now in the Victoria Nile focus will not transmit onchocerciasis.

Ov16 results in young children from Kiryandongo district along River Nile downstreatm from Lake Kyoga did not indicate exposure to $O$. volvulus. This result showed that Simulium vectors in this area were not infected with $O$. volvulus, and, therefore, posed no threat for reinfection of the Victoria Nile focus. Moreover, after leaving the Victoria Nile focus limits, the flow of River Nile toward Lake Kyoga is sluggish with a long stretch of papyrus, making it unsuitable for $S$. damnosum breeding. It was evident that the vectors from the nearest breeding sites downstream from Lake Kyoga in the districts of Kiryandongo and Oyam had not invaded the Victoria Nile focus for the past 46 years since 1973. Therefore, the Victoria Nile focus appeared secure from possible reinvasion by $O$. volvulus-infected $S$. damnosum. There are a number of onchocerciasis foci in Africa that were eliminated some years ago in Kenya ${ }^{1}$ and in other countries in West Africa that were under the management of Onchocerciasis Control Programme between 1994 and 2002 when it was closed. ${ }^{27}$ Such foci may require post-elimination surveillance (PES) based on the recent $\mathrm{WHO}$ verification guidelines before a country is declared free of onchocerciasis. ${ }^{19}$ Interestingly, the Victoria Nile Onchocerciasis focus that was eliminated about 46 years ago offers an approach to verifying onchocerciasis elimination in
(01) Victoria
(02) Wadelai
(0) Mpamba-Nkusi
(04) Itwara
(05) Mt. Elgon
(06) Imaramagambo
(07) Kashoya-Kitomi
(08) Wambabya-Rwamarongo
(09) Budongo
(10) Bwindi
(11) Maracha-Terego
(12) Nyagak-Bondo
(13) Obongi
(14) Lhubiriha
(15) Nyamugasani
(16) West Nile
(17) Madi Mid North

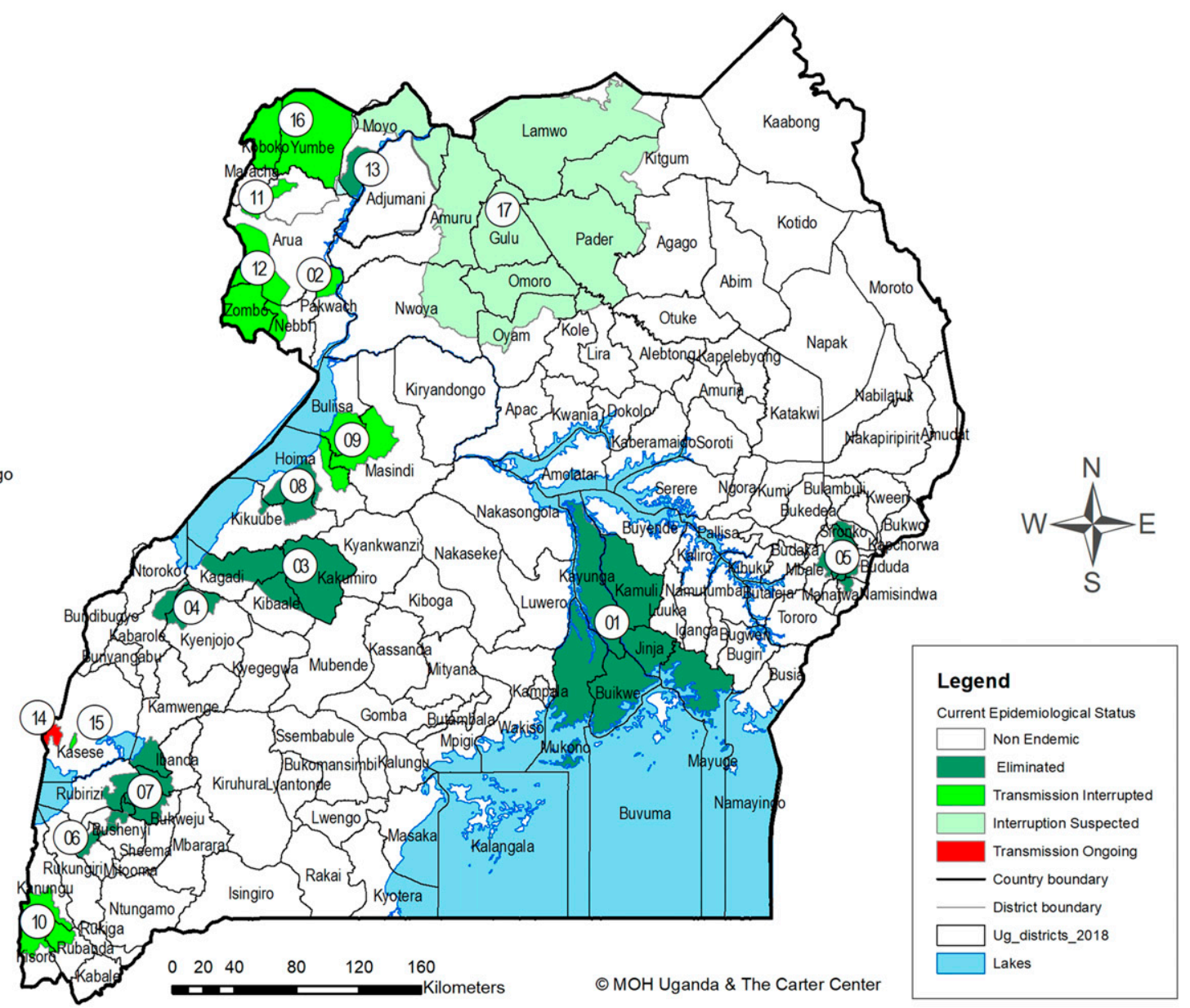

FIGURE 4. Progress of onchocerciasis elimination in Uganda by 2019. 
Kenya during the $1960 s^{8}$ and in some foci in former Onchocerciasis Control Programme countries of West Africa, which are currently in the PES phase before they are declared free from onchocerciasis. $^{27}$

Nakalanga syndrome, which has been associated with onchocerciasis, was rampant in the Victoria Nile focus in the 1950s and $1960 \mathrm{~s}^{7}$ and was not examined during the recent entomological and serological surveys reported here. We recommend that future studies should investigate the current status of the Nakalanga syndrome and community knowledge of the disease in the population in the eliminated onchocerciasis focus. It is important to know whether Nakalanga syndrome, a condition previously associated with onchocerciasis, is still of public health importance in an area where onchocerciasis elimination was verified.

\section{CONCLUSION}

It has been at least about 46 years since onchocerciasis was first thought to have been eliminated in the Victoria Nile focus through vector control with DDT, and the vectors have never returned to Victoria Nile focus. The evidence reported here demonstrates that onchocerciasis in Victoria Nile focus was indeed eliminated, according to the current WHO criteria. Therefore, Victoria Nile focus has joined seven other onchocerciasis foci (Kashoya-Kitomi, Imaramagambo, Itwara, Mount Elgon, Mpamba-Nkusi, Wambabya-Rwamarongo, and Obongi foci) in Uganda that have been verified for onchocerciasis elimination using the current WHO guidelines (Figure 4).

Received January 24, 2020. Accepted for publication March 3, 2020. Published online March 30, 2020.

Acknowledgments: We would like to acknowledge the cooperation we received from the community members, and community and district leaders in Victoria Nile focus during serological and entomological assessment. We would also like to thank the fly collectors and health workers for their dedication in ensuring that the work was completed during the planned period. The late Hillary Kasibini, the retired vector control officer, worked with Prentice M. A. in this focus and guided us in identifying historic fly collection sites on which the entomological work was based. May his soul rest in eternal peace.

Authors' addresses: Moses N. Katabarwa, Lauri Bernard, and Frank Richards, Health Programs, The Carter Center, E-mails: moses. katabarwa@cartercenter.org, lauri.bernard@cartercenter.org, and frank.richards@cartercenter.org. Peace Habomugisha, Annet Khainza, and Edson Byamukama, Health Programs, The Carter Center, Kampala, Uganda, E-mails: peace.habo@cartercenter.org, annet.khainza@ cartercenter.org, and edson.byamukama@cartercenter.org. David W. Oguttu, Christine Nahabwe, Monica Ngabirano, and Paul Akampurira, Vector Control Division, Ministry of Health, Kampala, Uganda, E-mails: dguttu@gmail.com, ch.nahabwe@gmail.com, monicakembabazi12@ gmail.com, and mugyenyipaul@gmail.com. James Katamanywa, Vector Control, Fort Portal, Uganda, E-mail: katamanywawilly@gmail.com. Thomas R. Unnasch, Center for Global Health Infectious Disease Research, University of South Florida, Tampa, FL, E-mail: tunnasch@ usf.edu.

\section{REFERENCES}

1. Raybound JN, McCrae AWR, 1975. Expert Committee on Epidemiology of Onchocerciasis. Geneva, Switzerland: World Health Organization. 10-18 November 1975.

2. Barnley GR, 1975. Onchocerciasis, Uganda Atlas of Disease Distribution. Nairobi, Kenya: East African Publishing, 38-40.

3. Sasa M, 1976. Human Filariasis, A Global Survey of Epidemiology and Control. Tokyo, Japan: University of Tokyo Press, 88-90.
4. Gibbins EG, 1935. "Mbwa" flies. Uganda J 2: 272-277.

5. Dunbar RW, 1966. Four sibling species included in Simulium damnosum theobald (Diptera: Simuliidae) from Uganda. Nature 209: 597-599.

6. Vajime CG, Dunbar RW, 1975. Chromosomal identification of eight species of the subgenus Edwardsellum near and including simulium (Edwardsellum) damnosum Theobald (Diptera: Simuliidae). Tropenmed Parasitol 26: 111-138.

7. Gibbons EG, Loewenthal LJA, 1933. Cutaneous onchocerciasis in a Simulium damnosum-infected region of Uganda. Ann Trop Med Parasitol 27: 489-496.

8. Raybound JN, Whte GB, 1979. The distribution, bionomics, and control of onchocerciasis vectors (Diptera: Simuliidae) in east Africa and the Yemen. Tropenmed Parasitol 30: 505-547.

9. Okello DO, Ovuga EB, Ogwal-Okeng JW, 1995. Dermatological problems of onchocerciasis in Nebbi district, Uganda. East Afr Med J 72: 295-298.

10. Ovuga EB, Okello DO, Ogwal-Okeng JW, Orwotho N, Opoka RO, 1995. Social and psychological aspects of onchocercal skin disease in Nebbi district, Uganda. East Afr Med J 72: 449-453.

11. Raper AB, Ladkin RG, 1950. Endemic dwafism in Uganda. $E$ Afr Med J 27: 339-359.

12. Bagenda R, Batwala J, Stanfield JP, 1964. Banakalanga: Domiciliary study into definitions and attitudes. East Afr Med J 41: 324-332.

13. McCrae AWR, 1986. The effects of a single insecticide dose on a Nile population of S. damnosum. Newsl Br Simuliid Group 12: 2-10.

14. Prentice MA, ed. 1974. Simulium control program in Uganda, 1974. Research and Control of Onchocerciasis in the Western Hemisphere: Proceedings of an International Symposium, Washington, DC: Research and Control of Onchocerciasis in the Western Hemisphere. 18-21 November 1974, 87-93.

15. Brown AW, 1962. A survey of Simulium control in Africa. Bull World Health Organ 27: 511-527.

16. McMahon JP, 1967. A review of the control of Simulium vectors of onchocerciasis. Bull Bull World Health Organ 37, 415-430.

17. Colbourne MJ, Crosskey RW, 1965. Onchocerciasis and its Control in Uganda (Mimeographed Document Afr/Oncho/ 8Rev1, WHO/ONCHO/30.65 Rev.l) Geneva, Switzerland: World Health Organization.

18. McCrae AWR, 1978. Intermittent eradication of Simulium damnosum Theo. On the nile from Jinja., Uganda: 1951-1977. Service MW, ed. Medical Entomology Centenary Symposium Proceedings. London, United Kingdom: Transactions of the Royal Society of Tropical Medicine and Hygiene, 133-134.

19. World Health Organization, 2016. Guidelines for Stopping Mass Drug Administration and Verifying Elimination of Human onchocerciasis. Criteria and Procedures. Geneva, Switzerland: World Health Organization.

20. Oguttu D et al., 2014. Serosurveillance to monitor onchocerciasis elimination: the Ugandan experience. Am J Trop Med Hyg 90: 339-345.

21. Freeman P, de Meillon B, 1953. Simuliidae of the Ethiopian Region. London, United Kingdom: British Museum (Natural History), 224.

22. Crosskey RW, 1993. Simuliidae. Lane RL, Crosskey RW, eds. Medical Insects and Arachnids. London, United Kingdom: Chapman \& Hall, 723.

23. Gopal H, Hassan HK, Rodríguez-Pérez MA, Toé LD, Lustigman S, Unnasch TR, 2012. Oligonucleotide based magnetic bead capture of Onchocerca volvulus DNA for PCR pool screening of vector black flies. PLoS Neg/ Trop Dis 6: e1712.

24. Katabarwa MN et al., 2018. After 70 years of fighting an age-old scourge, onchocerciasis in Uganda, the end is in sight. Int Health 10 (Suppl_1): i79-i88.

25. Hendy A et al., 2018. The black fly vectors and transmission of onchocerca volvulus in Mahenge, south eastern Tanzania. Acta Trop 181: 50-59.

26. Wegesa P, 1970. Simulium nyasalandicum (Amani form) and $S$. adersi, two new potential vectors of Onchocerca volvulus in the Eastern Usambaras, north-eastern Tanzania. E Afr Med $J$ 47: 364-367.

27. Traore MO et al., 2012. Proof-of-principle of onchocerciasis elimination with ivermectin treatment in endemic foci in Africa: final results of a study in Mali and Senegal. PLoS Negl Trop Dis 6: e1825. 